1 Post-print version of 'Jato-Espino, D., Indacoechea-Vega, I., Gáspár, L., 2 Castro-Fresno, D. (2018). "Decision support model for the selection of as3 phalt wearing courses in highly trafficked roads". Soft Comput., DOI: 4 10.1007/s00500-018-3136-7’.

5 


\title{
Decision support model for the selection of asphalt wearing courses in highly-trafficked roads
}

\author{
Daniel Jato-Espino*1, Irune Indacoechea-Vega², László Gáspár³, Daniel Castro- \\ Fresno $^{4}$ \\ 1,2,4 GITECO Research Group, Universidad de Cantabria, Av. de los Castros 44, 39005 Santander, Spain \\ ${ }^{3}$ KTI (Institute for Transport Sciences), 3-5 Thán Károly Street, H-1119 Budapest, Hungäry \\ E-mail addresses: jatod@unican.es (D. Jato-Espino), indacoecheai@unican.es (I. Indacoechea- \\ Vega), gaspar@kti.hu (L. Gáspár), castrod@unican.es (D. Castro-Fresno) \\ * Corresponding author. Tel.: +34 9422039 43; fax: +34 942201703.
}

\begin{abstract}
The suitable choice of the materials forming the wearing course of highly-trafficked roads is a delicate task because of their direct interaction with vehicles. Furthermore, modern roads must be planned according to sustainable development goals, which is complex because some of these might be in conflict. Under this premise, this paper develops a multi-criteria decision support model based on the Analytic Hierarchy Process (AHP) and the Technique for Order of Preference by Similarity to Ideal Solution (TOPSIS) to facilitate the selection of wearing courses in European countries. Variables were modelled either using Fuzzy Logic or Monte Carlo Methods, depending on their nature. The views of a panel of experts on the problem were collected and processed using the Generalized Reduced Gradient (GRG) algorithm and a Distance-based Aggregation approach. The results showed a clear preponderance by Stone Mastic Asphalt over the remaining alternatives in different scenarios evaluated through sensitivity analysis. The research leading to these results was framed in the European FP7 project "DURABROADS” (nº 605404).
\end{abstract}

\section{Keywords}

AHP; Fuzzy Logic; Monte Carlo Methods; Multi-criteria decision-making; Road management; TOPSIS 


\section{Introduction}

43

44

45

46

47

48

49

50

51

52

53

54

55

56

57

58

59

60

61

62

63

64

65

66

67

68

69

70

71

72

73

74

75

76

77

Roads were one of the greatest contributors to the changing environment during the second half of the $20^{\text {th }}$ century in European countries. These infrastructures have become essential for daily life as they play a crucial role in transporting people and goods and providing access to services. In consequence, roads have an important influence on their surrounding economic activity, while generating social benefits, either direct or indirect, for the parties communicated (Collins \& Africa 2017; Đukicin Vuckovic et al. 2017; Joumard \& Nicolas 2010). They also produce relevant environmental impacts due to the materials and processes involved in their construction and use. Furthermore, roads must be designed to withstand the vehicle loads of their installation site, especially if they are intended to support high traffic levels. According to the TEN-T road network information system (European Comission 2014), the number of equivalent single axle loads (ESALs) for highly-trafficked European roads would be above 25 million for a period of analysis of 24 years. Among the different layers forming road structures, the wearing course is the most sensitive one to these loads, because of its direct exposure to them.

Under these circumstances, which entail considering several conflicting factors, the need for a decision system for the selection of wearing courses from an integral point of view is fully justified. Multi-criteria decision analysis (MCDA) is a branch of operations research aimed at helping to make better decisions by applying analytical methods to solve complex problems characterized by having multiple criteria. In other words, MCDA supports the resolution of problems consisting of the evaluation of a group of alternatives $A_{i}\langle i=1,2, \ldots, m\rangle$ with respect to a set of criteria $C_{j}\langle j=1,2, \ldots, n\rangle$, in order to select the best solution among those contemplated.

Some authors have previously analysed several issues related to road management characterised by the presence of multiple conflicting criteria or attributes from different perspectives. Chou (1990) designed a decision-making tool to help engineers to design reliable pavements according to the values of several mechanical parameters. Davis and Campbell (1995) developed a decision support system based on the contribution of several criteria to an objective function for ranking different pavement materials. Cafiso et al. (2002) checked the applicability of the Analytic Hierarchy Process (AHP) for pavement maintenance management. Chang et al. (2005) used the Technique for Order Preference by Similarity to Ideal Solution (TOPSIS) to compare different preventive treatments for pavement maintenance according to economic and technical criteria. Filippo et al. (2007) proposed a fuzzy AHP model to prioritize the restoration of paved highways from an environmental point of view. Based on an overview of existing multi-attribute decision support approaches, Zavadskas et al. (2007) selected the COPRAS method to assess different road design alternatives. Some of the same authors carried out a deeper review on the use of decision support tools in bridges and road quality management (Zavadskas et al. 2008). They concluded that multi-attribute analysis might be especially 
helpful in management and planning tasks, whilst cost benefit analysis is mainly used for final project selection. Wu et al. (2008) combined mutiobjective optimization and prioritization of criteria using the AHP method to create a decision support model for pavement preservation budgeting. Van Leest et al. (2009) compared various types of road pavements according to factors such as costs, risks, safety or emissions. Brauers et al. (2008) employed the Multi-Objective Optimization on the basis of the Ratio Analysis (MOORA) to select the best alternative of highway design according to five objectives related to economy, environment and longevity. Sivilevičius led the development of two research papers (Sivilevicius et al. 2008; Sivilevicius 2011) aimed at assessing the quality of Asphalt Mixing Plants (AMP) using multi-attribute models. Bian and Cai (2012) applied the AHP method to rank the performance of asphalt pavement crack repairing materials and select the most appropriate one according to the evaluation result. Lidicker et al. (2013) solved a multi-criteria optimization problem to minimize the life-cycle costs and greenhouse gas emissions of pavement resurfacing. Moretti et al. (2013) measured the global environmental impact of road works from cradle to grave through the Weighted Sum Model (WSM). Kucukvar et al. (2014) studied four alternatives of pavement mixtures according to environmental and socio-economic indicators using an intuitionistic fuzzy decision-making approach based on the TOPSIS method. Jato-Espino et al. (2014) proposed a hybrid model based on the MIVES and AHP methods to assist the selection procedure of urban pervious pavements. Noori et al. (2014) presented a stochastic optimization approach based on multiple criteria for the selection of reflective cracking mitigation techniques.

The above-mentioned studies did not jointly addressed these infrastructures from the triple point of view of sustainability, which is crucial to ensure the selection of cost-effective road materials in harmony with environmental preservation and social welfare. For this reason, this paper aimed at developing a decision support model to facilitate the choice of wearing courses in highly-trafficked European roads. To this end, a comprehensive approach based on the combination of the AHP and TOPSIS methods was conceived. Data to characterize the performance of various wearing courses were generated by combining the information obtained from both literature sources and the opinions provided by a panel of recognized international experts in the topic under study. Other complements such as Fuzzy Logic, the Generalized Reduced Gradient (GRG) algorithm, Monte Carlo Methods and Distance-based Aggregation were also introduced to deal with some specifics of this decision-making problem. Finally, sensitivity analysis was conducted to gain insight into how changing some of the inputs used to build the model affected the final ranking of alternatives. 


\section{Methodology}

121 The proposed multi-criteria decision-making methodology was outlined as an algorithm consisting of five main steps, as depicted in Figure 1: (1) definition of the decision-making problem, (2) processing of questionnaires, (3) weighting of criteria, (4) assessment of alternatives and (5) sensitivity analysis. The next subsections describe in detail all the operations required to accomplish each of these five steps.

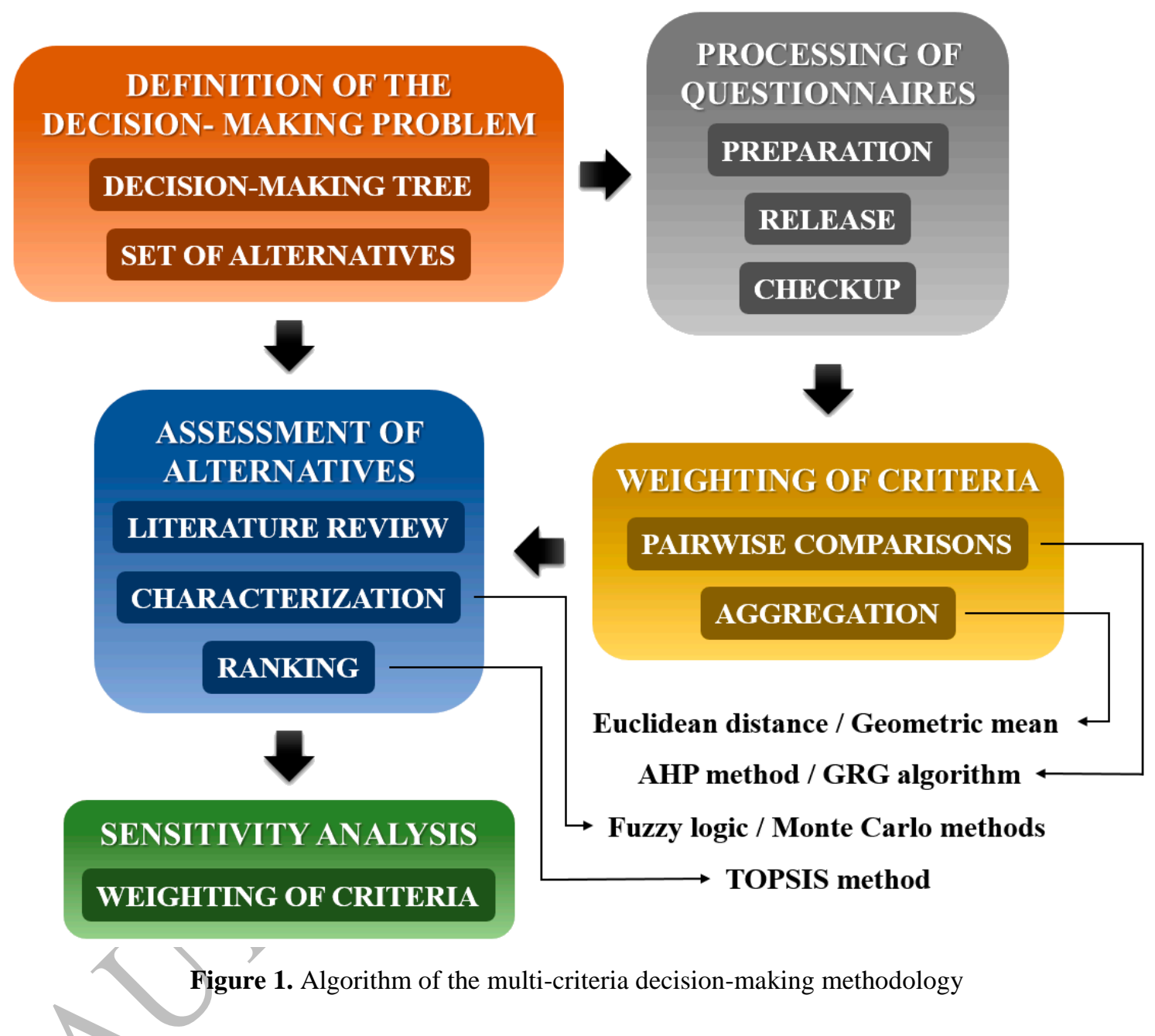

\subsection{Definition of the decision-making problem}

To ensure the choice of wearing courses meeting the principles of sustainability, they were assessed according to the concept of lifetime engineering. Lifetime engineering is based on using technical performance parameters, so that roads are capable of fulfilling economic, environmental and social requirements throughout their whole life cycle (Sarja 2010). These are conflicting aspects, since the satisfaction of some of them might result in the dissatisfaction of some others. This fact justified the need for a methodology based on multi-criteria decision-making theory to properly analyse all these aspects together. 
The economic requirement was characterized through the cradle-to-grave costs in-

140 volved by wearing courses. Since these variables are subject to continuous market fluc-

141 tuations, they were defined through ranges of values expressing different degrees of like-

142 lihood of achieving a certain cost. The main environmental impacts associated with road

143 pavements were summarized in the consumption of non-renewable resources (fuel and

144 aggregates) and greenhouse gas emissions, whose main contributor is carbon dioxide

$145\left(\mathrm{CO}_{2}\right)$. As in the economic requirement, these factors were also evaluated throughout the

146 lifecycle of the materials involved and according to ranges of estimates. From the point

147 of view of the users of the wearing courses, the social aspects to consider were grouped

148 into two criteria: comfort and safety. The first group referred to indicators concerning

149 driving quality, while safety represented the interaction of the pavement surface with both

150 the wheels of vehicles and drivers' visibility. Finally, key technical indicators were pro-

151 posed based on methodologies for new and reconstructed pavements, as well as pavement

152 performance monitoring methods (Litzka et al. 2008). These indicators were related to

153 the mechanical behaviour of the wearing courses in terms of deformation and disintegra-

154 tion.

155 The breakdown of these four requirements into more specific levels (criteria and in-

156 dicators) resulted in a hierarchical tree-shaped structure as shown in Table 1.This set of

157 indicators was subjected to discussion among the members of the project in which this

158 study was framed (DURABROADS, Ref.605404), in order to gather their opinions about

159 those originally proposed and suggest the addition or removal of some of them. There

160 were only two variations in relation to the initial proposal. Firstly, the technical require-

161 ment was divided into two criteria, disintegration and deformation resistance, which were

162 further broken down into two (fatigue and thermal cracking) and one (rutting resistance)

163 indicators, respectively. Secondly, the environmental requirement included a fourth cri-

164 terion, namely recyclability, which was represented through an indicator about the recy-

165 clability rate of the asphalt mixtures. In the end, the technical requirement was summa-

166 rized as shown in Table 1, since the experts suggested that the characterization of specific

167 functional variables might be difficult to approach, whilst recyclability was finally dis-

168 carded because the alternatives were found to be very homogenous in these terms, such

169 that the contribution of this indicator to the analysis would have been insignificant. 
Table 1. Decision-making tree for the selection of wearing courses

\begin{tabular}{|c|c|c|c|c|c|}
\hline$R_{j_{1}}$ & Requirements & $C_{j_{1} j_{2}}$ & Criteria & $I_{j_{1} \cdot j_{2} \cdot j_{3}}$ & Indicators \\
\hline \multirow[t]{2}{*}{$R_{1}$} & Economy & $C_{1.1}$ & Costs & $\begin{array}{ll}1.1 .1 \\
\end{array}$ & Initial Investment $\left(€ / \mathrm{m}^{2}\right)$ \\
\hline & & & & $I_{1.1 .2}$ & Life Cycle Cost $\left(€ / \mathrm{m}^{2} \cdot \mathrm{yr}\right)$ \\
\hline \multirow{4}{*}{$R_{2}$} & Environment & $C_{2.1}$ & Resource Efficiency & $I_{2.1 .1}$ & Aggregate Usage $\left(\mathrm{kg} / \mathrm{m}^{2} \cdot \mathrm{yr}\right)$ \\
\hline & & & & $I_{2.1 .2}$ & Bitumen Usage $\left(\mathrm{kg} / \mathrm{m}^{2} \cdot \mathrm{yr}\right)$ \\
\hline & & $C_{2.2}$ & Consumptions & $I_{2.2 .1}$ & Energy Consumption $\left(\mathrm{MJ} / \mathrm{m}^{2} \cdot \mathrm{yr}\right)$ \\
\hline & & $C_{2.3}$ & Emissions & $I_{2.3 .1}$ & $\mathrm{CO}_{2}$ Emissions $\left(\mathrm{kg} / \mathrm{m}^{2} \cdot \mathrm{yr}\right)$ \\
\hline \multirow[t]{4}{*}{$R_{3}$} & Society & $C_{3.1}$ & Comfort & $I_{3.1 .1}$ & Ride Quality (Score) \\
\hline & & & & $I_{3.1 .2}$ & Noise (Score) \\
\hline & & $C_{3.2}$ & Safety & $I_{3.2 .1}$ & Skid Resistance (Score) \\
\hline & & & & $I_{3.2 .2}$ & Hydroplaning \& Visibility (Score) \\
\hline \multirow[t]{2}{*}{$R_{4}$} & Technique & $C_{4.1}$ & Mechanical Resistance & $I_{4.1 .1}$ & Disintegration Resistance (Score) \\
\hline & & & & $I_{4.1 .2}$ & Deformation Resistance (Score) \\
\hline
\end{tabular}

172

173

174

175

176

177

178

179

180

181

182

183

184

185

186

187

188

189

190

191

192

193

The alternatives to be assessed with respect to this decision-making tree were established from the specifications found in the European Standard EN 13108 "Bituminous mixtures" (CEN 2008) and a survey of members of the DURABROADS project about the most widely used asphalt wearing courses in the European regions to which they belong. As a result, the five different alternatives shown in Table 2 emerged.

Table 2. Set of alternatives for the selection of wearing courses

\begin{tabular}{ll}
\hline $\boldsymbol{A}_{\boldsymbol{i}}$ & Alternative \\
\hline$A_{1}$ & Asphalt Concrete (AC) \\
$A_{2}$ & Very Thin Asphalt Concrete (BBTM) \\
$A_{3}$ & Hot Rolled Asphalt (HRA) \\
$A_{4}$ & Porous Asphalt (PA) \\
$A_{5}$ & Stone Mastic Asphalt (SMA) \\
\hline
\end{tabular}

\subsection{Processing of questionnaires}

Since part of the methodology relied on the opinions of a panel of experts in road management, well-prepared questionnaires were needed for both outlining the decision-making problem and capturing the expertise of the respondents. They were conceived to be concise, understandable and easy to fill in. Under these premises, two types of questionnaires were created to gather the information required to carry out the steps of weighting of criteria and assessment of alternatives.

They both were developed in MS Excel spreadsheets (Microsoft Corporation 2013), in order to use a familiar format for all the parties involved. A short introduction describing the aim of the questionnaires and the way they should be filled in was provided to put the addressees into context. The procedure was very simple, since the experts only had to answer questions like "How important is criterion $j_{1}$ with respect to criterion $j_{2}$ " and 
198

199

200

201

202

203

204

205

206

207

208

209

210

211

212

213

214

215

216

217

218

219

220

"How is the behaviour of alternative $i$ with respect to criterion $j$ ?", according to the two scales of options listed in Table 3.

Table 3. Linguistic scales of opinion for weighting the criteria and assessing the alternatives

\begin{tabular}{ll}
\hline Weighting of criteria & Assessment of alternatives \\
\hline Absolutely less important & Extremely poor \\
Much less important & Very poor \\
Less important & Poor \\
Slightly less important & Medium poor \\
Equally important & Fair \\
Slightly more important & Medium good \\
More important & Good \\
Much more important & Very good \\
Absolutely more important & Extremely good \\
\hline
\end{tabular}

Several partners of the DURABROADS project and other representatives from both private and public sectors with extensive knowledge of the road industry formed the panel of experts who provided their opinions concerning the weights of criteria and the rating of alternatives, which resulted in 52 institutions represented by 81 different experts. After discarding those questionnaires sent back without being completely filled in, the valid outputs were reduced to 74 and 25 valid judgments for weighting the criteria and assessing the alternatives summarized in Table 1 and Table 2, respectively.

\subsection{Weighting of criteria}

This phase sought to process the valid questionnaires according to the importance given to the elements shown in Table 1, in order to obtain their relative weights. To this end, the pairwise comparisons provided by the experts according to Table 3 were related to the preference scale of the Analytic Hierarchy Process (AHP).

\subsubsection{Analytic Hierarchy Process (AHP)}

The Analytic Hierarchy Process, originally created by Saaty (1980), is one of the most widely used methods to establish the weights of a set of criteria defining a decision-making problem. Saaty (1980) proposed the numeric scale shown in Table 4 to quantify the the linguistic terms used to establish the pairwise comparisons between two elements. 
Table 4. Saaty's comparison scale

\begin{tabular}{lr}
\hline Linguistic term $\left(\boldsymbol{j}_{\mathbf{1}}\right.$ with respect to $\left.\boldsymbol{j}_{\mathbf{2}}\right)$ & Numerical value \\
\hline Absolutely less important & $1 / 9$ \\
Much less important & $1 / 7$ \\
Less important & $1 / 5$ \\
Slightly less important & $1 / 3$ \\
Equally important & 1 \\
Slightly more important & 3 \\
More important & 5 \\
Much more important & 7 \\
Absolutely more important & 9 \\
\hline
\end{tabular}

The arrangement of the values used to compare a set of criteria yields an $n \times n$ reciprocal matrix $[M]$ consisting of elements that verify the expression $A_{j_{1} j_{2}} * A_{j_{2} j_{1}}=1$. The consistency of these comparisons is measured through the maximum eigenvalue of $[M]$ $\left(\lambda_{\max }\right)$. Hence, $[M]$ is completely consistent when $\lambda_{\max }=n$, while it becomes increasingly inconsistent as the eigenvalue grows, according to the Eq. (1):

$$
\text { C.R. }=\frac{\text { C.I. }}{\text { R.I. }}<0.1
$$

where $C . R$. is the consistency ratio, C.I. is the consistency index and R.I. is the random consistency index. A matrix is consistent when the ratio between $C$. I. and $R$. I. is less than 0.1 , such that $C . I$. is expressed as formulated in Eq. (2):

$$
\text { C.I. }=\frac{\lambda_{\max }-n}{n-1}
$$

$R$.I. represents an averáge $C$. $I$. for a large number of randomly generated matrices of the same order. Table 5 shows the average value of $R$. $I$. for a sample size of 500 matrices.

Table 5. Random consistency index

\begin{tabular}{llllllllllll}
\hline Matrix size $(\boldsymbol{n})$ & 2 & 3 & 4 & 5 & 6 & 7 & 8 & 9 & 10 \\
\hline R.I. & 0.00 & 0.58 & 0.90 & 1.12 & 1.24 & 1.32 & 1.41 & 1.45 & 1.49 \\
\hline
\end{tabular}

The measurement of the consistency of pairwise comparison matrices is a widely discussed topic in literature, which provides multiple evidence of the theoretical drawbacks associated with its original characterization based on Eqs. (1) and (2) and Table 5 (Bozóki and Rapcsák 2008; Dijkstra 2013; Grzybowski 2016; Peláez and Lamata 2003). Hence, forcing the comparison matrix to be consistent has been argued to be artificial and create certain dependencies that might lead to loose information and yield poor priorities (Bana 
e Costa and Vansnick 2008; Grzybowski 2012; Koczkodaj 1993). However, using reciprocal matrices might result in less pairwise comparisons, improving the response rate for the questionnaire and increasing the accuracy of the responses provided by the experts addressed (Miller 1956). To deal with this duality, the consistency of valid questionnaires was checked by applying Eq. (1). Those questionnaires showing inconsistencies were not discarded, but were made consistent by adjusting them through nonlinear optimization.

\subsubsection{Generalized Reduced Gradient (GRG) algorithm for nonlinear optimization}

The GRG algorithm, proposed by Abadie \& Carpentier (1969) as an extension of the reduced gradient method (Wolfe 1963), was developed to solve nonlinear programming problems of the form of Eq. (3):

258

259

260

261

262

263

264

265

266

267

268

269

270

271

272

273

274

275

276

277

$$
\begin{array}{ll}
\text { Minimize } f(X), \quad x \in \mathbb{R}^{n} \\
\text { subject to: } & g_{i}(X)=0, \quad 1 \leq i \leq m \\
& X_{\min } \leq X \leq X_{\max }
\end{array}
$$

where $X$ is a vector of $n$ variables, $f(X)$ is the objective function and $g_{i}(X)$ are nonlinear constraints. Kao (1998) highlighted the GRG algorithm as one of the best deterministic methods for the solution of nonlinear programming problems. Although the improvement of consistency in pairwise comparisons using optimization methods has been previously addressed in literature (Koczkodaj and Szarek 2010), existing approaches are either linear or too complex in terms of computer modelling to be very widespread yet (Benítez et al. 2012; Bozóki et al. 2011). These factors are against the nonlinear nature of the problem under study and hinder the automation of the entire methodology, respectively.

The working principle of the GRG algorithm consists of transforming nonlinear problems into several linearized sub-problems by approximating its constraints and then solving each sub-problem with linear restrictions using the reduced gradient method (Yeniay 2005). This conversion is carried out by representing some of the variables contained in $X$, called basics, through a subset of independent variables called non-basics (de Carvalho et al. 2008). Further details on the GRG method can be consulted in Lasdon et al. (1978).

The approach taken in this study was simpler, since only the objective function was nonlinear. Let $[M]$ be the inconsistent comparison matrix provided by an expert with respect to a set of criteria $C_{j}=\left\langle C_{1}, C_{2}, \ldots, C_{n}\right\rangle$ (see Eq. (4)). 


$$
\begin{array}{cc|cccc} 
& \boldsymbol{C}_{\mathbf{1}} & \boldsymbol{C}_{\mathbf{2}} & \ldots & \boldsymbol{C}_{\boldsymbol{n}} \\
\hline \boldsymbol{C}_{\mathbf{1}} & 1 & x_{12} & \ldots & x_{1 n} \\
\boldsymbol{C}_{\mathbf{2}} & 1 / x_{12} & 1 & \ldots & x_{2 n} \\
\ldots & \ldots & \ldots & \ldots & \ldots \\
\boldsymbol{C}_{\boldsymbol{n}} & 1 / x_{1 n} & 1 / x_{2 n} & \ldots & 1
\end{array}
$$

In addition, let $[M]^{\prime}$ be the consistent matrix being sought. The aim was to minimize the differences between the elements forming the upper right triangles of both matrices, while fulfilling Eq. (1) and remaining within their lower and upper bounds (see Table 4). In other words, the goal was to estimate the real views that some experts were not able to provide due to the rigidity of the discrete comparison scale proposed by Saaty. To this end, the differences between both matrices were measured through the Root Mean Square Error (RMSE), which is a metric regularly employed to model errors in statistical analyses (Chai and Draxler 2014). Therefore, the problem was stated as expressed in Eq. (5):

$$
\text { Minimize } \sqrt{\frac{1}{n} \sum_{j=1}^{n}\left(\ln x_{j_{1} j_{2}}-\ln x_{j_{1} j_{2}}^{\prime}\right)^{2}}
$$

subject to: $\quad$ C.R. $\leq 0.1$

$$
\ln x_{j_{1} j_{2}}^{L . B .}<\ln x_{j_{1} j_{2}}^{\prime}<\ln x_{j_{1} j_{2}}^{U . B .}
$$

Since the scale shown in Table 4 is based on reciprocal values, the numerical judgments provided by the experts were transformed into a logarithmic scale before applying Eq. (5), in order to equalize the differences between lower and higher levels of importance. The resolution of this problem obliged the comparison matrix to be consistent (first constraint), while respecting the responses provided by the experts as much as possible (second constraint). The second restriction was a reflection of the difficulties often associated with the choice between terms such as "more important" or "slightly more important" when responding to this kind of questionnaires. Moreover, the combination of both restrictions acted as a quality measure, enabling the discarding of those questionnaires proving to be too inconsistent.

\subsubsection{Distance-based Aggregation}

The next step consisted of aggregating all the questionnaires returned by the experts into a single one reflecting the consensual view of the entire panel. As a result of the previous step, some elements forming the comparison matrix were no longer discrete and became 
305

continuous, which means that there might be intermediate degrees of importance in addition to those shown in Table 4. For this reason, the Euclidean distance (see Eq. (6)), which is the most common metric when measuring similarities between clusters (Xing et al. 2003), was proposed for assessing the affinity between the points of view of the experts:

$$
s_{e_{k} e_{l}}=\sqrt{\sum_{j=1}^{n}\left(x_{j_{1} j_{2}, e_{k}}-x_{j_{1} j_{2}, e_{l}}\right)^{2}}
$$

where $s_{e_{k} e_{l}}$ is the distance between the thoughts of experts $e_{k}$ and $e_{l}$, while $x_{j_{1} j_{2}, e_{k}}$ and $x_{j_{1} j_{2}, e_{l}}$ are the numerical expressions of their judgments regarding the relative importance of criterion $j_{1}$ with respect to $j_{2}$.

The calculation of the Euclidean distance for each expert with respect to the remaining experts resulted in a symmetric $p \times p$ matrix $[P]$ (see Eq. (7)), such that $p$ is the number of experts. $[P]$ reflected the proximity between the points of view of each pair of experts.

$$
[P]=\begin{array}{c|cccc} 
& \boldsymbol{e}_{\mathbf{1}} & \boldsymbol{e}_{\mathbf{2}} & \ldots & \boldsymbol{e}_{\boldsymbol{p}} \\
\hline \boldsymbol{e}_{\mathbf{1}} & 0 & s_{e_{1} e_{2}} & \ldots & s_{e_{1} e_{p}} \\
\boldsymbol{e}_{\mathbf{2}} & s_{e_{2} e_{1}} & 0 & \ldots & s_{e_{2} e_{p}} \\
\ldots & \ldots & \ldots & \ldots & \ldots \\
\boldsymbol{e}_{\boldsymbol{p}} & s_{e_{p} e_{1}} & s_{e_{p} e_{2}} & \ldots & 0
\end{array}
$$

The next task was to give a weight to each expert according to the similarity of thought they showed with respect to the remaining experts. Thus, the opinions of those experts having shorter distances were more important when determining the final weights of criteria and vice versa. This was accomplished by calculating the weighted inverse of the sum of the distances from each expert to the remaining experts, as represented in Eq. (8).

$$
w_{e_{k}}=\frac{1 / \sum_{k=1}^{p} s_{e_{k} e_{l}}}{\sum_{k=1}^{p}\left(1 / \sum_{k=1}^{p} s_{e_{k} e_{l}}\right)}
$$

In accordance with the studies carried out by Aczél and Saaty (1983) and Aczél and Alsina (1987), the weighted geometric mean (the weighted mean of $g$ numbers expressed as the $g^{\text {th }}$ root of their product), not the often used weighted arithmetic mean, was used to aggregate the individual opinions of the experts into a single consensual judgment $\left(x_{j_{1} j_{2}, c}\right)$ through Eq. (9): 


$$
x_{j_{1} j_{2}, c}=\left(\prod_{k=1}^{p} x_{j_{1} j_{2}, e_{k}}^{\prime} w_{e_{k}}\right)^{1 / \sum_{k=1}^{p} w_{e_{k}}}
$$

332

333

334

335

336

337

338

339

340

341

342

343

344

345

346

347

348

349

350

351

352

353

These consensual judgments were then arranged in a consensual comparison matrix $\left[M_{c}\right]$ as expressed in Eq. (10):

$$
\begin{array}{cc|cccc} 
& \boldsymbol{C}_{\mathbf{1}} & \boldsymbol{C}_{\mathbf{2}} & \ldots & \boldsymbol{C}_{\boldsymbol{n}} \\
\left.\hline M_{c}\right]= & 1 & x_{12, c} & \ldots & x_{1 n, c} \\
\boldsymbol{C}_{\mathbf{1}} & \boldsymbol{C}_{\mathbf{2}} & x_{21, c} & 1 & \ldots & x_{2 n, c} \\
\ldots & \ldots & \ldots & \ldots & \ldots \\
\boldsymbol{C}_{\boldsymbol{n}} & x_{n 1, c} & x_{n 2, c} & \ldots & 1
\end{array}
$$

The final calculation of the weights of criteria was preceded by the normalization of the elements of $\left[M_{c}\right]$ according to Eq. (11):

$$
x_{j_{1} j_{2}, c n}=\frac{x_{j_{1} j_{2}, c}}{\sqrt{\sum_{j=1}^{n} x_{j_{2}, c}}}
$$

Finally, the values contained in the normalized consensual comparison matrix enabled the determination of the weights of criteria $C_{j}=\left\langle C_{1}, C_{2}, \ldots, C_{n}\right\rangle$ using Eq. (12):

$$
w_{j}=\frac{\sum_{j=1}^{n} \frac{1}{\sqrt{\sum_{j=1}^{n} x_{j_{1} j_{2}, c}}}}{\sum \sum_{j=1}^{n} \frac{1}{\sqrt{\sum_{j=1}^{n} x_{j_{1} j_{2}, c}}}}
$$

\subsection{Assessment of alternatives}

The aim of this phase was to rank the alternatives from the processing of their ratings with respect to the criteria. In this respect, Table 1 highlighted by containing two different types of criteria: qualitative and quantitative. Qualitative variables were processed using fuzzy logic by combining the knowledge acquired from literature and the opinions provided by the group of experts, both expressed in linguistic terminology. Instead, quantitative variables were modelled through Monte Carlo simulations according to ranges of likely numerical values according to specialised literature. 
Once the ratings of the alternatives were expressed and processed in one of the two ways mentioned above, they were used as inputs to establish their ranking using the Technique for Order of Preference by Similarity to Ideal Solution (TOPSIS). TOPSIS is a compensatory aggregation method, which means that a decrease in a certain criterion might be compensated by an increase in another. Although the compensation of some of the elements included in Table 1 might seem undesirable and there are operators to prevent these situations (Jato-Espino et al. 2016), the extra parameters and formulations required to implement them led to not considering additional approaches to deal with this matter.

363

\subsubsection{Literature review}

365

366

A scientific review was carried out to assess the performance of the wearing courses under consideration with respect to the indicators defined in Table 1 . The studies conducted by Nicholls et al. (2012) and Nikolaides (2008; 2014) were taken as the main references to rate wearing courses from a functional point of view, since they enabled the comparative analysis of all the alternatives considered in Table 2 in terms of their noise, ride and waterrelated performance, as well as their disintegration, deformation and skid resistance.

Unlike these indicators, which were directly rated from the values found in the bibliography and the opinions provided by the experts, the Life Cycle Cost and the environmental indicators were calculated for a period of analysis of 24 years (EAPA 2007; Kim 2014; OECD 2005) using the concept of Equivalent Uniform Annual Cost (EUAC) and the values found in both the Inventory of Carbon and Energy (ICE) (Hammond \& Jones 2008) and the research conducted by Chehovits \& Galehouse (2010), respectively. The $E U A C$ of each alternative, which stands for their average annual cost and takes into consideration the loss of value of money throughout time, was calculated for a discount rate of $4 \%$ according to Eq. (13).

$$
E U A C=\frac{P W C \cdot D R}{\left(1-\frac{1}{(1+D R)^{Y}}\right)}
$$

382

where $P W C$ is the present worth of costs, $D R$ the discount rate and $Y$ the years of analysis.

\subsubsection{Characterization}

386 
389 Qualitative variables were those too complex or of such a nature that their quantification

390 was not possible. The ratings of this kind of variables were defined according to linguistic 391 terms, which are very useful when characterizing vague situations. Zadeh (1965) devel392 oped the concept of fuzzy logic to account for the imprecision and ambiguity (i.e. the 393 fuzziness) inherent to language statements.

394 One of the most significant and intuitive ways to handle fuzziness is the use of fuzzy 395 numbers, whose definition includes the concept of membership degree. Zadeh (1965) 396 proposed that the range of membership values of an element of a set may vary within the 397 interval $[0,1]$, instead of having to be limited to one of the pair of values $\{0,1\}$. Thereby, 398 given a fuzzy set $F$, a fuzzy number can be characterized by a membership function $399 \mu_{T_{1}}(f)$ that represents the grade of membership of $f$ in $F$ (Lin 2010). For the sake of 400 simplicity, triangular fuzzy numbers (TFN) were chosen to model qualitative variables. 401 The membership function of a triangular fuzzy number $\widetilde{T_{1}}=(\alpha, \beta, \gamma)$ can be represented 402 as shown in Eq. (14):

403

$$
\mu_{T_{1}}(f ; \alpha, \beta, \gamma)= \begin{cases}\frac{f-\alpha}{\beta-\alpha}, & \alpha \leq z \leq \beta \\ \frac{\gamma-f}{\gamma-\beta}, & \beta \leq z \leq \gamma \\ 0, & \text { otherwise }\end{cases}
$$

404

405 where $\alpha, \beta$ and $\gamma$ are the lower, middle and upper values of the triangular fuzzy number $406 \widetilde{T_{1}}$. Table 6 shows the scale of the triangular fuzzy numbers used in this study to represent 407 linguistic terms.

408

409

Table 6. Linguistic terms for rating qualitative variables

\begin{tabular}{lc}
\hline Linguistic term & TFN \\
\hline Extremely poor & $(1,1,2)$ \\
Very poor & $(1,2,3)$ \\
Poor & $(2,3,4)$ \\
Medium poor & $(3,4,5)$ \\
Fair & $(4,5,6)$ \\
Medium good & $(5,6,7)$ \\
Good & $(6,7,8)$ \\
Very good & $(7,8,9)$ \\
Extremely good & $(8,9,9)$ \\
\hline
\end{tabular}


Again, the ratings provided by the panel of experts regarding the performance of these qualitative variables was synthesized into a single one, but taking into account that in this 413 case there were ratings proceeding from literature as well.

Let $r_{i j}$ be the rating of a certain alternative $A_{i}$ with respect to a criterion $C_{j}$. The distance between the points of view of two experts $e_{k}$ and $e_{l}$ who have expressed their lin416 guistic ratings $r_{i j}$ through two triangular fuzzy numbers $\widetilde{T_{1}}=\left(\alpha_{T_{1}}, \beta_{T_{1}}, \gamma_{T_{1}}\right)$ and $\widetilde{T_{2}}=$ $417\left(\alpha_{T_{2}}, \beta_{T_{2}}, \gamma_{T_{2}}\right)$ was approximated using the vertex method (Jahanshahloo et al. 2006): 418

$$
s_{e_{k} e_{l}}=\sqrt{\frac{1}{3}\left[\left(\alpha_{T_{1}}-\alpha_{T_{2}}\right)^{2}+\left(\beta_{T_{1}}-\beta_{T_{2}}\right)^{2}+\left(\gamma_{T_{1}}-\gamma_{T_{2}}\right)^{2}\right]}
$$

419

420

421

422

423

424

425

426

427

428

429

430

431

432

433

434

435

436

437

438

439

440

441

where $s_{e_{k} e_{l}}$ is the distance between the thoughts of experts $e_{k}$ and $e_{l}$ with respect to a variable defined using the TFNs $\widetilde{T_{1}}$ and $\widetilde{T_{2}}$.

The weight of each expert and the consensual rating for the whole panel of experts were calculated according to Eqs. (8) and (9), respectively. The rating acquired from literature was incorporated into the process through the geometric mean as formulated in Eq. (16):

$$
\widetilde{r_{l j}}=\sqrt{\widetilde{r_{l j}^{E}} \times \widetilde{r_{l j}^{L}}}
$$

where $\widetilde{r_{l j}}$ is the final rating of alternative $A_{i}$ with respect to criterion $C_{j}, \widetilde{r_{l j}^{E}}$ is the consensual rating provided by the panel of experts and $\widetilde{r_{l j}^{L}}$ is the rating taken from specialized literature.

In order to produce a simple and manageable value, those variables described through triangular fuzzy numbers were expressed by their canonical representation based on the graded mean integration method (Chou 2003). Given a triangular fuzzy number $\widetilde{T_{1}}=$ $(\alpha, \beta, \gamma)$, its graded mean integration representation was defined as in Eq. (17):

$$
P\left(\widetilde{T_{1}}\right)=\frac{1}{6}(\alpha+4 \times \beta+\gamma)
$$

Thus, Eq. (17) enabled the conversion from the triangular fuzzy numbers obtained in Eq. (16) to crisp numbers, which is very useful in simplifying the TOPSIS method.

\section{Monte Carlo methods to process uncertain quantitative variables}


442 Quantitative variables are those which can be modelled through crisp numbers. However,

443 real-life situations are subject to uncertainty, which hinders their definition using a single

444 and monolithic number. For this reason, quantitative variables were handled stochasti-

445 cally from ranges of likely values using Monte Carlo methods, which enabled determin-

446 ing the probability of achieving different performances according to ranges of estimates.

447 These techniques are based on the generation of random numbers to find approximate

448 solutions to problems that are unapproachable using analytical procedures (Hammersley

449 and Handscomb 1964). In this context, they were employed to examine the uncertainty

450 associated with the different scenarios assumed to establish the ranges of estimates of the

451 indicators. These indicators were characterized by a trio of numbers: their most likely 452 value, acquired from expertise and/or bibliographic references, and lower and upper 453 bounds indicating minimum and maximum achievable values (Vose 1996).

454 Therefore, the application of these techniques required selecting a distribution func455 tion tending to favour the most likely value from which to generate random numbers. The 456 triangular shape, which associates each of its vertices with the aforementioned trio of 457 values, was chosen for being the simplest and least computationally demanding option 458 for this purpose and, consequently, the easiest means to combine this technique with the 459 remaining techniques and models included in the proposed methodology. Hence, the gen460 eration of triangularly distributed random numbers yielded a vector containing $t$ different 461 ratings $r_{i j}$, such that $t$ is the number of simulations carried out with triangularly distrib462 463 uted random numbers, instead of a single number $r_{i j}$.

\subsubsection{Technique for Order of Preference by Similarity to Ideal Solution (TOPSIS)}

The TOPSIS method, originally developed by Hwang \& Yoon (1981), is based on the principle that the preferred alternative to a given multi-criteria problem is not only characterized by having the shortest distance to the positive ideal solution $\left(A^{+}\right)$, but also the longest distance to the negative ideal solution $\left(A^{-}\right)$. Handling the duality of these two concepts is not a trivial matter, since the nearest alternative to the positive ideal solution is not necessarily the same as the farthest from the negative ideal solution. The TOPSIS

1) Define the decision-making matrix. The decision-making matrix shows the ratings respect to the criteria $C_{j}\langle j=1,2, \ldots, n\rangle$. 
478

479

480

481

482

483

484

485

486

487

488

489

490

491

492

493

494

495

496

497

\begin{tabular}{c|cccc} 
& $\boldsymbol{C}_{\mathbf{1}}$ & $\boldsymbol{C}_{\mathbf{2}}$ & $\ldots$ & $\boldsymbol{C}_{\boldsymbol{n}}$ \\
\hline $\boldsymbol{A}_{\mathbf{1}}$ & $r_{11}$ & $r_{12}$ & $\ldots$ & $r_{1 n}$ \\
$\boldsymbol{A}_{\mathbf{2}}$ & $r_{21}$ & $r_{22}$ & $\ldots$ & $r_{2 n}$ \\
$\ldots$ & $\ldots$ & $\ldots$ & $\ldots$ & $\ldots$ \\
$\boldsymbol{A}_{\boldsymbol{m}}$ & $r_{m 1}$ & $r_{m 2}$ & $\ldots$ & $r_{m n}$
\end{tabular}

2) Normalize the decision-making matrix. Normalized ratings $u_{i j}$ are calculated as:

$$
u_{i j}=\frac{r_{i j}}{\sqrt{\sum_{i=1}^{m} r_{i j}^{2}}}, \quad i=1,2, \ldots, m ; j=1,2, \ldots, n
$$

3) Construct the normalized weighted decision-making matrix. Normalized weighted ratings $v_{i j}$ are determined as:

$$
v_{i j}=w_{j} \times u_{i j}, \quad i=1,2, \ldots, m ; j=1,2, \ldots, n
$$

where $w_{j}$ is the weight of the $j$ criterion, such that $\sum_{j=1}^{n} w_{j}=1$.

4) Determine the positive ideal solution $\left(A^{+}\right)$and negative ideal solution $\left(A^{-}\right)$.

$$
A^{+}=\left\{\left(\max _{i} v_{i j} \forall j \in J\right) \mid\left(\min _{i} v_{i j} \forall j \in J^{\prime}\right)\right\}
$$

$$
A^{-}=\left\{\left(\min _{i} v_{i j} \forall j \in J\right) \mid\left(\max _{i} v_{i j} \forall j \in J^{\prime}\right)\right\}
$$

where $J$ is associated with benefit criteria and $J^{\prime}$ is associated with cost criteria.

5) Calculate the distance of each alternative from $\boldsymbol{A}^{+}$and $\boldsymbol{A}^{-}$. Separation measures are determined using the $n$-dimensional Euclidean distance:

$$
d_{i}^{+}=\sqrt{\sum_{j=1}^{n}\left(v_{i j}-v_{j}^{+}\right)^{2}}, i=1,2, \ldots, m
$$




$$
d_{i}^{-}=\sqrt{\sum_{j=1}^{n}\left(v_{i j}-v_{j}^{-}\right)^{2}}, i=1,2, \ldots, m
$$

498

499

500

501

502

503

504

505

506

507

508

509

510

511

512

513

514

515

516

517

518

519

520

521

522

523

524

525

526

527

528

529

where $v_{j}^{+}$and $v_{j}^{-}$are the positive and negative ideal normalized weighted value for the criterion $j$, respectively.

6) Calculate the relative closeness from each alternative to the ideal solution. The relative closeness of the alternative $A_{i}$ with respect to the ideal solution is defined as:

$$
R C_{i}=\frac{d_{i}^{-}}{d_{i}^{+}+d_{i}^{-}}, \quad i=1,2, \ldots, m
$$

$$
\text { Since both } d_{i}^{+} \text {and } d_{i}^{-} \text {are zero or greater than zero, then } 0 \leq R C_{i} \leq 1 \text {. }
$$

\subsection{Sensitivity analysis}

In the context of the decision-making problem addressed in this study, sensitivity analysis consisted of determining how and how much specific changes in the weights of criteria and ratings of alternatives modified the relative closeness coefficients $\left(R C_{i}\right)$ obtained. Its inclusion was intended to avoid the simple satisfaction with the solution provided by the methodology by analysing how it responded to changes in the inputs.

Sensitivity analysis was conducted to assess the effects of climate change on the final ranking of alternatives provided by the TOPSIS method. According to the European Environment Agency (EEA 2014), these effects depend on the European Region under consideration. Thus, the largest temperature increases are projected in Southern Europe and the Arctic region, while precipitation is forecasted to increase in Northern and Western European regions and decrease in Southern regions. Sandberg et al. (2010) highlighted rainfall events, temperature (heat waves) and freeze-thaw cycles as the main effects of climate change on road surfaces. Members of the EARN project (Effects on Availability of Road Network) also studied the impact of climate change on roads (Tabaković et al. 2014). They reached similar conclusions to the Joint Research Centre (Nemry and Demirel 2012), which identified several impacts of different nature and severity depending on the region:

- Frequent freeze-thaw cycles in Northern countries.

- General warming in summer and more days with extreme maximum temperatures in Southern, Western and Central Europe. 
- Increase in the intensity of daily rainfall and the probability of extreme precipitation throughout Europe, especially in some regions located in Northern Europe.

Table 7 summarizes the expected effects of climate change on asphalt wearing courses after reviewing these data sources. In addition to future climate change impacts, another scenario (1a) was added to reflect the lower durability of asphalt surfacing in Northern countries (OECD 2005).

Table 7. Sensitivity analysis scenarios and likely impact on asphalt wearing courses

\begin{tabular}{|c|c|c|c|}
\hline Region & Scenario & Description & Impacts on wearing courses \\
\hline \multirow[t]{4}{*}{ North } & $1 \mathrm{a}$ & Lower durability of materials & $\downarrow$ Durability in LCC and LCA \\
\hline & & & $\uparrow$ Technique \\
\hline & $1 b$ & Climate change effects & $\uparrow$ Disintegration Resis \\
\hline & & & $\uparrow \uparrow$ Safety \\
\hline \multirow[t]{2}{*}{ South } & $2 \mathrm{a}$ & Short-term climate change & $\uparrow \uparrow$ Deformation Resistance \\
\hline & $2 b$ & climate & formation Resistance \\
\hline \multirow[t]{5}{*}{ West } & 3a & Short-term climate change & $\uparrow$ Technique \\
\hline & & & $\uparrow \uparrow$ Safety \\
\hline & $3 b$ & Long-term climate change & $\uparrow$ Technique \\
\hline & & & $\uparrow \uparrow$ Safety \\
\hline & & & $\uparrow \mathrm{CO}_{2}$ Emissions \\
\hline \multirow[t]{7}{*}{ Centre } & $4 a$ & Short-term climate change & $\uparrow$ Deformation Resistance \\
\hline & & & $\uparrow \uparrow$ Disintegration Resistance \\
\hline & & & $\uparrow$ Safety \\
\hline & & mate chanoe & $\uparrow$ Deformation Resistance \\
\hline & & & $\uparrow \uparrow$ Disintegration Resistance \\
\hline & & & $\uparrow$ Safety \\
\hline & & & $\uparrow \mathrm{CO} 2$ Emissions \\
\hline
\end{tabular}

538

\section{Results and discussion}

540

541 This section presents and discusses the results obtained in the three calculation phases of 542 the methodology: weighting of criteria, assessment of alternatives and sensitivity analy543 sis. The first was developed in MS Excel for convenience, since it was the format in which 544 questionnaires were received, whilst the two others were computed in MATLAB R2014b 545 (The MathWorks 2014), because of the need to loop through 3D matrices. 


\subsection{Weighting of criteria}

549 The application of the proposed methodology for processing and minimizing the incon550 sistencies of the questionnaires returned by the experts (see Eqs. (5), (6), (7), (8) and (9)) 551 yielded the consensual numerical values shown in Table 8 for the pairwise comparisons 552 among the elements shown in Table 1. The consensual comparison matrices were con553 sistent in all cases ( $C . R . \leq 0.1)$, which is logical considering that each individual compar554 ison matrix was made consistent using the GRG algorithm, whenever appropriate.

Table 8. Pairwise comparison values for the selection of wearing courses

\begin{tabular}{|c|c|c|c|}
\hline Level & Comparison & Numerical value & C.R. \\
\hline \multirow[t]{6}{*}{ Requirements } & $R_{1}$ vs $R_{2}$ & 0.709 & \\
\hline & $R_{1} v s R_{3}$ & 0.876 & \\
\hline & $R_{1}$ vs $R_{4}$ & 0.484 & \\
\hline & $R_{2} v s R_{3}$ & & \\
\hline & $R_{2} v s R_{4}$ & & \\
\hline & $R_{3}$ vs $R_{4}$ & 0.619 & \\
\hline \multirow[t]{4}{*}{ Criteria } & $C_{2.1}$ vs $C_{2.2}$ & 1.643 & \\
\hline & $C_{2.1}$ vs $C_{2}$ & 1.530 & 0.000 \\
\hline & $C_{2.2}$ vs $C$ & 0.902 & \\
\hline & $C_{3.1} v S C_{3.2}$ & 0.221 & 0.000 \\
\hline \multirow[t]{5}{*}{ Indicators } & $I_{1.1 .1} v S I_{1.1 .2}$ & 0.477 & 0.000 \\
\hline & $I_{2.1 .1}$ vs $I_{2.1 .2}$ & 0.450 & 0.000 \\
\hline & $I_{3.1 .1}$ vs $I_{3.1 .2}$ & 1.812 & 0.000 \\
\hline & $I_{3.2 .1}$ vs $I_{3.2 .2}$ & 2.458 & 0.000 \\
\hline & $I_{4.1 .1} v S I_{4.1 .2}$ & 1.000 & 0.000 \\
\hline
\end{tabular}

557
To illustrate how the pairwise comparisons provided by the experts were transformed after applying the distance-based aggregation approach, Figure 2 depicts the ranges of values found in the questionnaires for the most challenging level of comparisons (the four elements represented by the requirements), including the position of the consensual values achieved in Table 8 . The average $C$. $R$. reached with respect to this level was 0.118 , with $50.6 \%$ of the original comparisons being inconsistent by an average deviation of 0.099 from the threshold sought $(C . R .=0.1)$. However, since none of these comparisons was inconsistent enough to prevent the GRG algorithm to find a solution, they all were taken into account in the calculation of the consensual values. Their position in Figure 2 reaffirmed the convenience of adopting this course of action, proving not be affected by the existence of outliers, which were considered only marginally due to their distance to 
569 the majority of comparisons collected. This fact was especially noticeable in the compar570 ison between $R_{3}$ and $R_{4}$, where the consensual value was remarkably separated from the 571 median of the range of values provided by the experts.

572

573

574

575

576

577

578

579

580

581

582

583

584

585

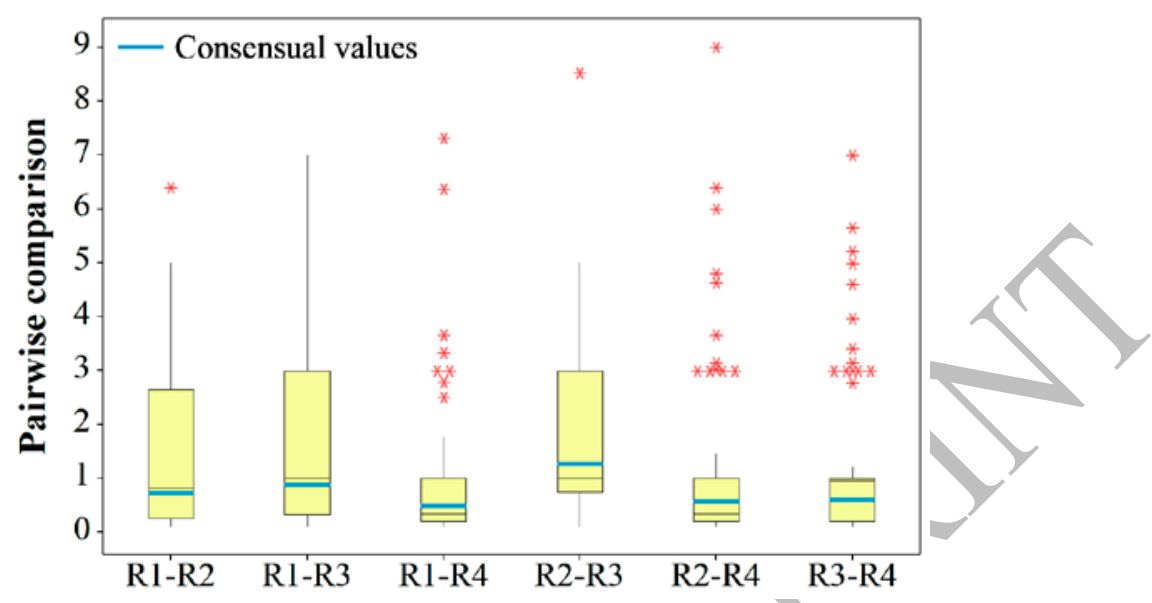

Figure 2. Comparison between the ranges of original comparisons provided by the experts for the requirements and the consensual values reached after applying the distance-based aggregation approach

As an example of using the GRG algorithm, Eq. (26) represents the inconsistent comparison matrix $(C . R .=0.275)$ returned by one expert regarding the importance of the four requirements:

\begin{tabular}{c|cccc} 
& $\boldsymbol{R}_{\mathbf{1}}$ & $\boldsymbol{R}_{\mathbf{2}}$ & $\boldsymbol{R}_{\mathbf{3}}$ & $\boldsymbol{R}_{\mathbf{4}}$ \\
\hline $\boldsymbol{R}_{\mathbf{1}}$ & 1 & 7 & 5 & $1 / 3$ \\
$\boldsymbol{R}_{\mathbf{2}}$ & $1 / 7$ & 1 & 5 & $1 / 5$ \\
$\boldsymbol{R}_{\mathbf{3}}$ & $1 / 5$ & $1 / 5$ & 1 & $1 / 5$ \\
$\boldsymbol{R}_{\mathbf{4}}$ & 3 & 5 & 5 & 1
\end{tabular}

After applying Eq. (5), the matrix was made consistent $(C . R .=0.1)$ while respecting as much as possible the original opinions provided by the expert (see Eq. (27)):

\begin{tabular}{c|cccc} 
& $\boldsymbol{R}_{\mathbf{1}}$ & $\boldsymbol{R}_{\mathbf{2}}$ & $\boldsymbol{R}_{\mathbf{3}}$ & $\boldsymbol{R}_{\mathbf{4}}$ \\
\hline $\boldsymbol{R}_{\mathbf{1}}$ & 1 & 5.151 & 5.446 & 0.416 \\
$\boldsymbol{R}_{\mathbf{2}}$ & 0.194 & 1 & 3.611 & 0.205 \\
$\boldsymbol{R}_{\mathbf{3}}$ & 0.184 & 0.277 & 1 & 0.157 \\
$\boldsymbol{R}_{\mathbf{4}}$ & 2.404 & 4.878 & 6.369 & 1
\end{tabular}


The use of Eqs. (11) and (12) from the values shown in Table 8 enabled the calculation of the weights of each element of the hierarchical decision-making tree, as shown in Table

588 9. The preponderance of the technical requirement over the others was noteworthy, which 589 can be explained by considering that a road with an adequate mechanical behaviour is 590 likely to present good economic and social performances too. The importance of the sec591 ond requirement clearly confirmed the increasing ecological awareness that exists in the 592 field of road engineering. Moreover, users' safety was the most relevant social factor 593 when planning the construction of asphalt wearing courses, which is in line with the con594 cerns of the European Commission (2006) in terms of road management.

595

596

597

Table 9. Weights of the elements for the selection of wearing courses

\begin{tabular}{cccccc}
\hline $\boldsymbol{R}_{\boldsymbol{j}_{\mathbf{1}}}$ & $\boldsymbol{w}_{\boldsymbol{j}_{\mathbf{1}}}$ & $\boldsymbol{C}_{\boldsymbol{j}_{\mathbf{1}} \boldsymbol{j}_{\mathbf{2}}}$ & $\boldsymbol{w}_{\boldsymbol{j}_{\mathbf{1}} \boldsymbol{j}_{\mathbf{2}}}$ & $\boldsymbol{I}_{\boldsymbol{j}_{\mathbf{1}} \boldsymbol{j}_{\mathbf{2}} \boldsymbol{j}_{\mathbf{3}}}$ & $\boldsymbol{I}_{\boldsymbol{j}_{\mathbf{1}} \boldsymbol{j}_{\mathbf{2}} \boldsymbol{j}_{\mathbf{3}}}$ \\
\hline$R_{1}$ & 0.178 & $C_{1.1}$ & 1.000 & $I_{1.1 .1}$ & 0.323 \\
& & & & $I_{1.1 .2}$ & 0.677 \\
\hline$R_{2}$ & 0.244 & $C_{2.1}$ & 0.442 & $I_{2.1 .1}$ & 0.310 \\
& & & & $I_{2.1 .2}$ & 0.690 \\
& & $C_{2.2}$ & 0.266 & $I_{2.2 .1}$ & 1.000 \\
& & $C_{2.3}$ & 0.292 & $I_{2.3 .1}$ & 1.000 \\
\hline$R_{3}$ & 0.209 & $C_{3.1}$ & 0.181 & $I_{3.1 .1}$ & 0.644 \\
& & & & $I_{3.1 .2}$ & 0.356 \\
& & $C_{3.2}$ & 0.819 & $I_{3.2 .1}$ & 0.711 \\
& & & & $I_{3.2 .2}$ & 0.289 \\
\hline$R_{4}$ & 0.369 & $C_{4.1}$ & 1.000 & $I_{4.1 .1}$ & 0.500 \\
& & & & $I_{4.1 .2}$ & 0.500 \\
\hline
\end{tabular}

\section{$598 \quad 3.2$. Assessment of alternatives}

599

600 Table 10 shows the ratings of each of the alternatives assessed with respect to the set of 601 indicators, Quantitative indicators were defined according to the range of values they 602 might adopt (minimum, most likely and maximum), whilst qualitative indicators were 603 expressed by their canonical representation, once Eq. (17) was applied. 
Table 10. Stochastic and canonical ratings for the indicators

\begin{tabular}{|c|c|c|c|c|c|c|}
\hline Indicator & Value & AC & BBTM & HRA & PA & SMA \\
\hline \multirow[t]{3}{*}{$I_{1.1 .1}$} & MIN & 0.34 & 0.34 & 0.29 & 0.50 & 0.40 \\
\hline & M.L. & 0.69 & 0.50 & 0.54 & 0.96 & 0.62 \\
\hline & MAX & 1.00 & 0.71 & 0.79 & 1.33 & 0.87 \\
\hline \multirow[t]{3}{*}{$I_{1.1 .2}$} & MIN & 3.10 & 2.90 & 3.60 & 3.40 & 4.30 \\
\hline & M.L. & 5.20 & 4.20 & 6.00 & 4.90 & 5.90 \\
\hline & MAX & 7.80 & 6.10 & 8.90 & 7.10 & 8.40 \\
\hline \multirow[t]{3}{*}{$I_{2.1 .1}$} & MIN & 21.22 & 16.12 & 15.15 & 24.36 & 17.19 \\
\hline & M.L. & 30.73 & 17.19 & 19.06 & 36.25 & 21.54 \\
\hline & MAX & 42.95 & 20.09 & 24.11 & 51.98 & 24.59 \\
\hline \multirow[t]{3}{*}{$I_{2.1 .2}$} & MIN & 1.00 & 0.85 & 1.05 & 1.09 & 1.00 \\
\hline & M.L. & 1.67 & 1.08 & 1.40 & 2.00 & 1.50 \\
\hline & MAX & 2.79 & 1.51 & 1.81 & 3.61 & 1.99 \\
\hline \multirow[t]{3}{*}{$I_{2.2 .1}$} & MIN & 3.51 & 2.76 & 2.92 & 107 & 3.05 \\
\hline & M.L. & 7.55 & 4.57 & 5.47 & 9.13 & 5.98 \\
\hline & MAX & 15.52 & 7.99 & 9.65 & 19.66 & 10.22 \\
\hline \multirow[t]{3}{*}{$I_{2.3 .1}$} & MIN & 0.25 & 0.19 & 0.20 & 0.29 & 0.21 \\
\hline & M.L. & 0.49 & 0.30 & 0.35 & 0.60 & 0.38 \\
\hline & MAX & 1.13 & 0.58 & 0.69 & 1.43 & 0.73 \\
\hline$I_{3.1 .1}$ & CAN & 6.96 & 6.77 & 6.70 & 7.79 & 7.81 \\
\hline$I_{3.1 .2}$ & CAN & 5.19 & 6.73 & 2.99 & 8.30 & 6.18 \\
\hline$I_{3.2 .1}$ & CAN & & 6.77 & 6.87 & 8.28 & 7.79 \\
\hline$I_{3.2 .2}$ & CAN & 3.15 & 6.52 & 3.31 & 8.67 & 7.03 \\
\hline$I_{4.1 .1}$ & CAN & 4.91 & 3.83 & 6.94 & 3.03 & 8.18 \\
\hline$I_{4.1 .2}$ & CAN & 6.15 & 6.67 & 5.20 & 8.19 & 8.23 \\
\hline
\end{tabular}

606

According to Tervonen \& Lahdelma (2007), a number of Monte Carlo simulations of 60810,000 was set to generate the triangularly distributed vectors for the quantitative indica609 tors, since this number of iterations was suggested to produce highly accurate results in 610 many real-life applications. The set of ratings $r_{i j}$ thus obtained was used to build the de611 cision-making matrices required to feed the TOPSIS method. Figure 3a) shows the rela612 tive closeness $\left(R C_{i}\right)$ of each of the alternatives to the ideal solution after following the 613 steps of the TOPSIS algorithm.

614 The overall performance of the alternatives was represented through their cumulative 615 probability functions, in order to capture the variability that characterizes both the eco616 nomic and environmental indicators. Hence, the final decision depends on the attitude of 617 the road designer towards uncertainty, because some alternatives might outperform others 618 according to the market fluctuations and the environmental conditions of each case. How619 ever, it is clear that the most likely ranking is $S M A>H R A>B B T M>A C>P A$. 


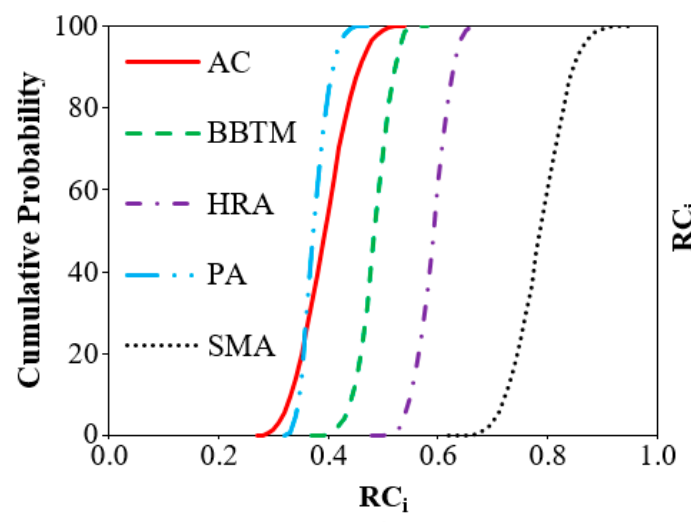

a)

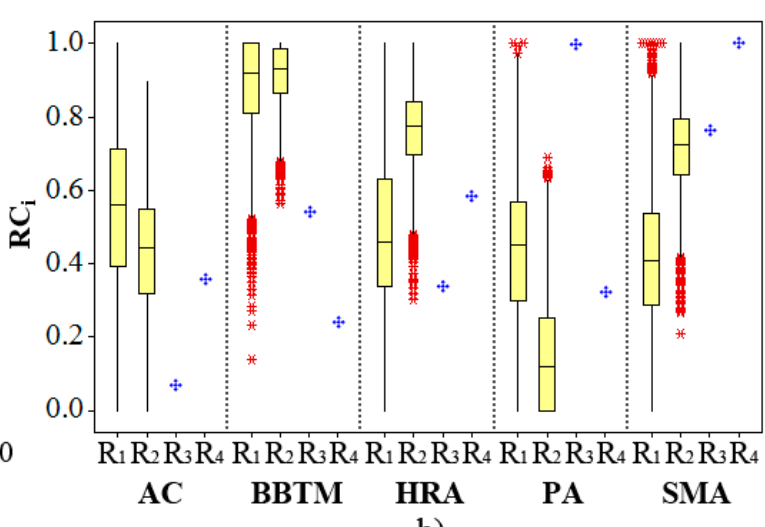

b)
622

623

624

625

626

627

628

629

630

631

632

633

634

635

636

637

638

639

640

641

642

643

644

645

646

647

648

649

650

Figure 3. a) Overall performance of wearing courses b) Performance of wearing courses with respect to the four requirements

The combined interpretation of Table 9 and Figure 3b) explains the reasons why the aforementioned ranking was achieved. The excellent behaviour of SMA in terms of technique, which was the most important requirement according to Table 9, was the principal cause of the first position of this alternative. The results also showed the importance of having a balanced behaviour with respect to conflicting criteria. In this sense, HRA achieved a notable overall performance by virtue of its at least decent ratings across the four requirements considered. In contrast, PA was severely affected by its poor disintegration resistance and negative environmental impact, in spite of being the best option from the social point of view and having a great deformation resistance. Similarly, the overall performance of BBTM, which was the cheapest and greenest wearing course, was strongly influenced by its low disintegration and fair deformation resistances.

\subsection{Sensitivity analysis}

The results of the sensitivity analysis for the selection of wearing courses (see Figure 4) reaffirmed the supremacy of SMA, which attained the highest $R_{i}$ for each of the scenarios proposed. Only the long-term consideration of climate change in South European countries decreased its superiority, since the increasing significance of $\mathrm{CO}_{2}$ emissions enabled BBTM and HRA to slightly reduce the difference. The main variations caused by the sensitivity analysis were related to the PA wearing course outranking AC and/or BBTM in several scenarios (1b, 3a, 3b and $4 a$ ) in which safety became even more relevant. In fact, only its weak disintegration resistance prevented PA from outperforming HRA too. In contrast, the poor behaviour of AC and BBTM in terms of skid resistance and disintegration resistance, respectively, made them less suitable in some scenarios for Western, Central and Northern European countries. 

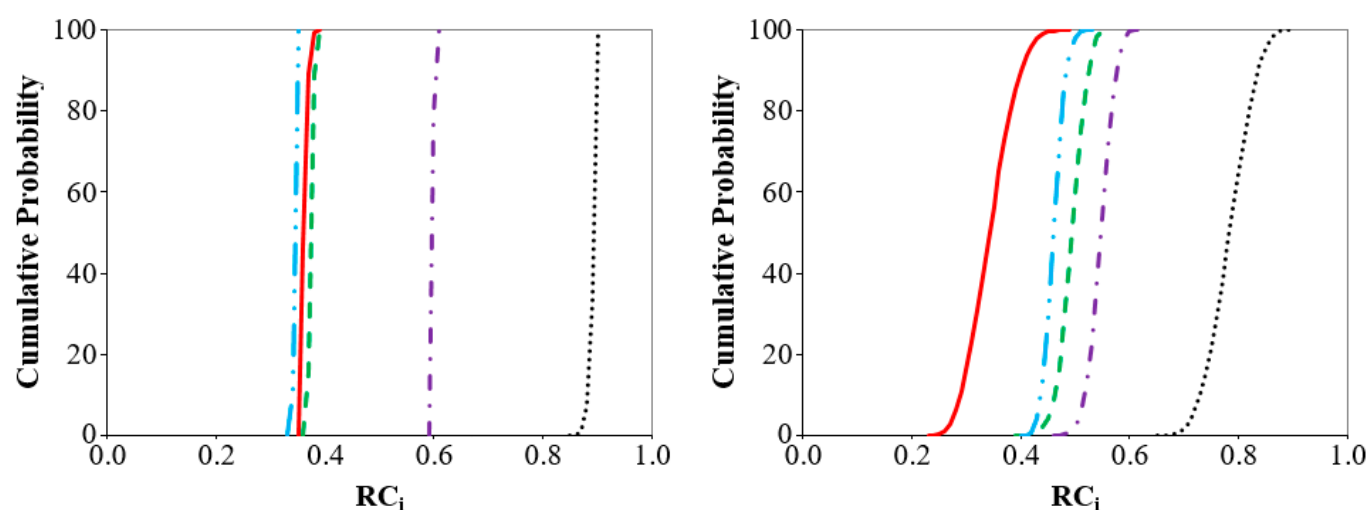

a)

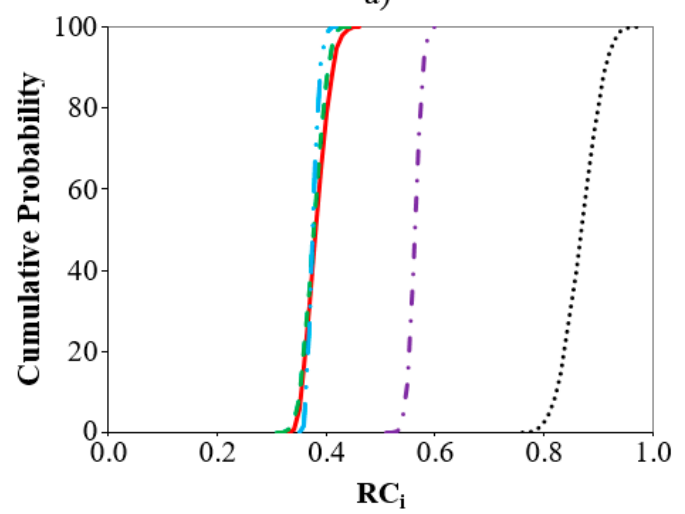

b)

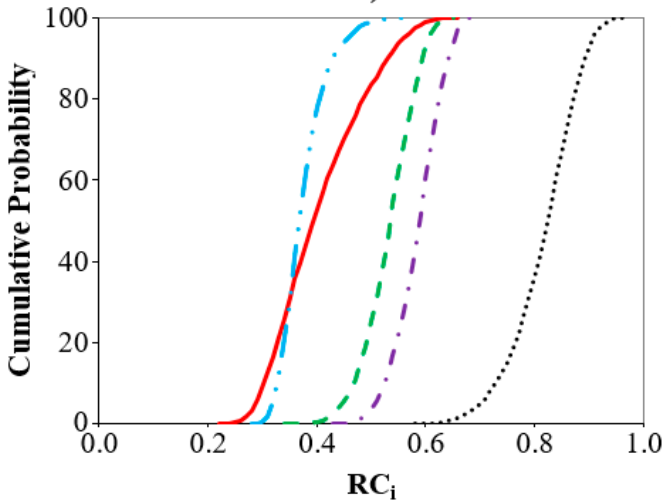

c)

d)
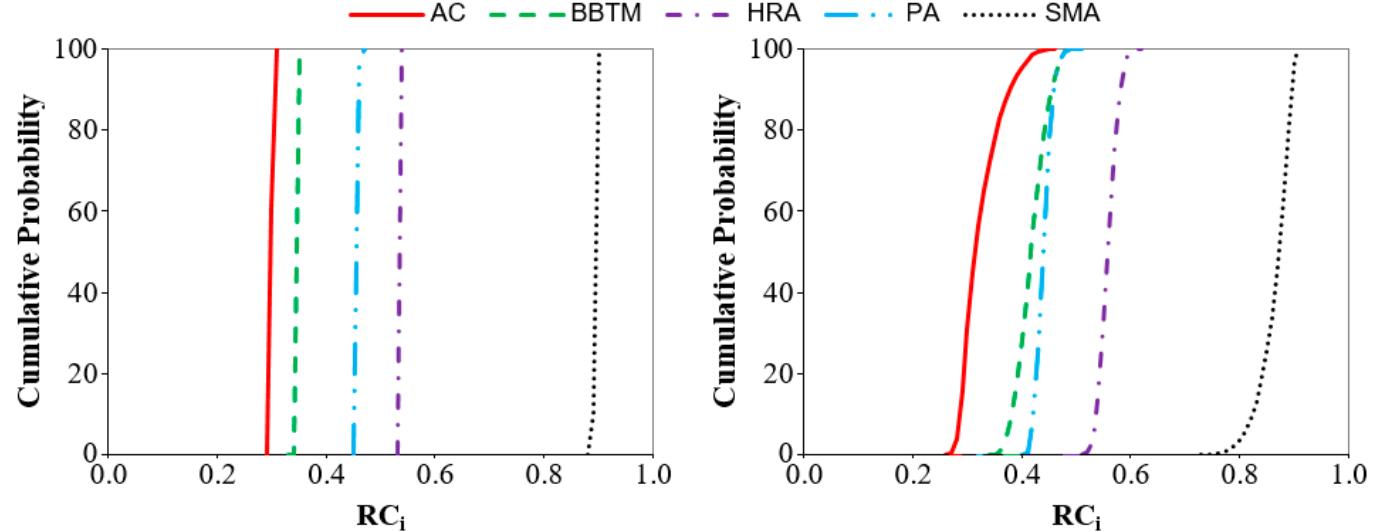

e)

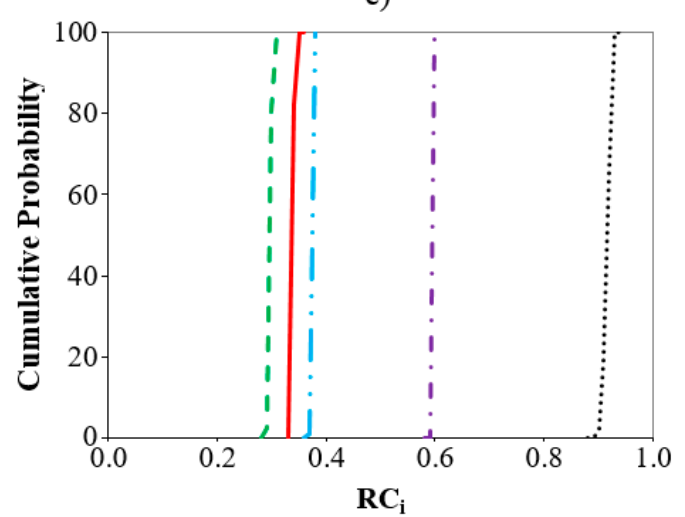

g)

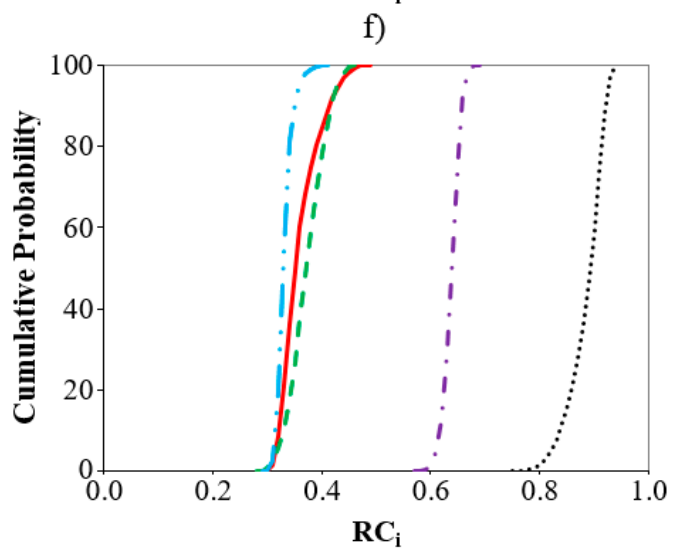

h)

Figure 4. Overall performance of wearing courses for the sensitivity analysis scenarios a) 1a b) 1b c) 2a 653 d) 2b e) 3a f) 3b g) 4a h) 4b 


\section{Conclusions}

655

656 This study proposed and applied a new decision support model for the selection of asphalt wearing courses based on the combination of the AHP and TOPSIS methods, including several additional complements such as Fuzzy Logic, Monte Carlo methods, GRG algorithm and Distance-based Aggregation. The synergetic performance of these components enabled building a comprehensive and robust methodology capable of dealing with aspects such as vagueness, uncertainty, inconsistency and engagement of experts' views, which are very common in complex decision-making environments.

The results showed the usefulness of the model and the clarity of vision it can provide when selecting the most suitable wearing course according to sustainable development criteria. Although the proper management of roads can have great positive impacts on economy, environment and society, there are few methodologies intended to assist this kind of selection processes, which further increases the importance and interest of the proposed model. Furthermore, the structuring of the decision-making problem in a hierarchical tree enables partial conclusions to be obtained about the performance of the alternatives with respect to a certain aspect or factor influencing them.

The automation capacity of the model was demonstrated through the sensitivity analysis carried out to represent different European regions. The architecture and algorithms forming the methodology were programmed to avoid altering the system operation when varying the inputs, which is a crucial issue to enable the use of this model by non-experts in the underlying analytical theory and methods. In addition, its flexibility allows the introduction of the set of weights and ratings known or calculated by each user, depending on the data sources available. Further research in this line should consider the design of a web-based interface capable of linking all the operations required to solve the addressed problem in an interactive and visual way, enabling the choice of all or some of the methods and techniques included in the proposed model, in order to promote its use among practitioners and decision-makers.

684

685

\section{Acknowledgments}

The research leading to these results has received funding from the European Union Seventh Framework Programme [FP7/2007-2013] under grant agreement $n^{\circ}$ [605404]. This paper reflects only the authors' views and the Community is not liable for any use that may be made of the information contained therein. The authors wish to thank the participants of the DURABROADS Work Package 2 (ACCIONA Infraestructuras S.A., European Union Road Federation and Inzenierbuve SIA) for their inestimable contribution to the research. 


\section{References}

694

Abadie, J., Carpentier, J. (1969). Generalization of the wolfe reduced gradient method to the case of nonlinear constraints. In R. Fletcher (Ed.), Optimization (pp. 37-47). London (U.K.): Academic Press.

Aczél, J., Alsina, C. (1987). Synthesizing judgements: A functional equations approach.

700

701

702

703

704

705

706

707

708

709

710

711

712

713

714

715

716

717

718

719

720

721

722

723

724

725

726

727

728

729 Mathematical Modelling, 9(3-5), 311-320. doi:10.1016/0270-0255(87)90487-8

Aczél, J., Saaty, T. L. (1983). Procedures for synthesizing ratio judgements. Journal of Mathematical Psychology, 27(1), 93-102. doi:10.1016/0022-2496(83)90028-7

Bana e Costa, C. A., Vansnick, J. -. (2008). A critical analysis of the eigenvalue method used to derive priorities in AHP. European Journal of Operational Research, 187(3), 1422-1428. doi:10.1016/j.ejor.2006.09.022

Benítez, J., Delgado-Galván, X., Izquierdo, J., Pérez-García, R. (2012). Improving consistency in AHP decision-making processes. Applied Mathematics and Computation, 219(5), 2432-2441. doi:10.1016/j.amc.2012.08.079

Bian, F., Cai, H. (2012). Choice of crack repairing material for asphalt pavement based on AHP. Journal of Testing and Evaluation, 40(7), 1-4. doi:10.1520/JTE20120154

Bozóki, S., Fülöp, J., Koczkodaj, W. W. (2011). An LP-based inconsistency monitoring of pairwise comparison matrices. Mathematical and Computer Modelling, 54(1-2), 789-793. doi:10.1016/j.mcm.2011.03.026

Bozóki, S., Rapcsák, T. (2008). On Saaty's and Koczkodaj's inconsistencies of pairwise comparison matrices. Journal of Global Optimization, 42(2), 157-175. doi:10.1007/s10898-007-9236-Z

Brauers, W. K. M., Zavadskas, E. K., Peldschus, F., Turskis, Z. (2008). Multi-objective decision-making for road design. Transport, 23(3), 183-193. doi:10.3846/16484142.2008.23.183-193

Cafiso, S., Di Graziano, A., Kerali, H. R., Odoki, J. B. (2002). Multicriteria analysis method for pavement maintenance management. Transportation Research Record, 1816(1816), 73-84.

Bituminous mixtures - Material specifications, 1 (2008).

Chai, T., Draxler, R. R. (2014). Root mean square error (RMSE) or mean absolute error (MAE)? -arguments against avoiding RMSE in the literature. Geoscientific Model Development, 7(3), 1247-1250. doi:10.5194/gmd-7-1247-2014

Chang, J. -., Chen, D. -., Hung, C. -. (2005). Selecting preventive maintenance treatments in texas : Using the technique for order preference by similarity to the ideal solution for specific pavement study-3 sites. Transportation Research Record, 1933(1933), $62-71$. 
730

731

732

733

734

735

736

737

738

739

740

741

742

743

744

745

746

747

748

749

750

751

752

753

754

755

756

757

758

759

760

761

762

763

764

765

766

767

Chehovits, J., Galehouse, L. (2010). Energy usage and greenhouse gas emissions of pavement preservation processes for asphalt concrete pavements. Okemos, Michigan (U.S.): National Centre for Pavement Preservation.

Chou, C. -. (2003). The canonical representation of multiplication operation on triangular fuzzy numbers. Computers and Mathematics with Applications, 45(10-11), 16011610. doi:10.1016/S0898-1221(03)00139-1

Chou, Y. T. (1990). Relaibility design procedures for flexible pavements. Journal of Transportation Engineering, 116(5), 602-614.

Collins, F., \& Africa, B. (2017). Infrastructure development as a key driver of sustainable social and economic development. 24th Annual FIDIC-GAMA Conference. 1-5.

Davis, C. F., Campbell, G. M. (1995). Selection of pavement markings using multicriteria decision making. Transportation Research Record, 1509(1509), 28-37.

de Carvalho, E. P., dos Santos, A., Ma, T. F. (2008). Reduced gradient method combined with augmented lagrangian and barrier for the optimal power flow problem. Applied Mathematics and Computation, 200(2), 529-536. doi:10.1016/j.amc.2007.11.025

Dijkstra, T. K. (2013). On the extraction of weights from pairwise comparison matrices. Central European Journal of Operations Research, 21(1), 103-123. doi:10.1007/s10100-011-0212-9

Đukicin Vuckovic, S., Đordevic, J., Milankovic Joyanov, J., Ivanovic Bibic, L., Protic, B., Đordevic, T., \& Ivkov, M. (2017). The development of transport infrastructure and attitudes of the local population: A case study from the republic of serbia. Geografisk Tidsskrift - Danish Journal of Geography, 1-13. doi:10.1080/00167223.2017.1419369

EAPA. (2007). Long-life asphalt pavements - technical version. Brussels (Belgium): European Asphalt Pavement Association.

EEA. (2014). Adaptation of transport to climate change in europe. ( No. 8). Luxembourg: European Environment Agency. doi:10.2800/56672

European Comission. (2014). Core network corridors. ( No. 13).

European Commission. (2006). Examples of assessed road safety measures. ROSEBUD - Road Safety and Environmental Benefit-Cost and Cost-Effectiveness Analysis for use in Decision-Making, 1, 7-66.

Filippo, S., Martins Ribeiro, P. C., Kahn Ribeiro, S. (2007). A fuzzy multi-criteria model applied to the management of the environmental restoration of paved highways. Transportation Research Part D: Transport and Environment, 12(6), 423-436. doi:10.1016/j.trd.2007.05.004

Grzybowski, A. Z. (2012). Note on a new optimization based approach for estimating priority weights and related consistency index. Expert Systems with Applications, 39(14), 11699-11708. doi:10.1016/j.eswa.2012.04.051 
Grzybowski, A. Z. (2016). New results on inconsistency indices and their relationship with the quality of priority vector estimation. Expert Systems with Applications, 43, 197-212. doi:10.1016/j.eswa.2015.08.049

Hammersley, J. M., Handscomb, D. C. (1964). Monte carlo methods. London (U.K.): Springer.

Hammond, G. P., Jones, C. I. (2008). Embodied energy and carbon in construction materials. Proceedings of Institution of Civil Engineers: Energy, 161(2), 87-98. doi:10.1680/ener.2008.161.2.87

Hwang, C. L., Yoon, K. (1981). Multiple attribute decision making: Methods and applications. New York (U.S.): Springer.

Jahanshahloo, G. R., Lotfi, F. H., Izadikhah, M. (2006). Extension of the TOPSIS method for decision-making problems with fuzzy data. Applied Mathematics and Computation, 181(2), 1544-1551. doi:10.1016/j.amc.2006.02.057

Jato-Espino, D., Rodriguez-Hernandez, J., Andrés-Valeri, V. C., Ballester-Muñoz, F. (2014). A fuzzy stochastic multi-criteria model for the selection of urban pervious pavements. Expert Systems with Applications, 41(15), 6807-6817. doi:10.1016/j.eswa.2014.05.008

Jato-Espino, D., Blanco-Fernandez, E., Carpio-García, J., Castro-Fresno, D. (2016). Decision aid system founded on nonlinear valuation, dispersion-based weighting and correlative aggregation for wire rope selection in slope stability cable nets. Expert Systems with Applications, 54, 148-154. doi:10.1016/j.eswa.2016.01.023

Joumard, R., \& Nicolas, J. -. (2010). Transport project assessment methodology within the framework of sustainable development. Ecological Indicators, 10(2), 136-142. doi:10.1016/j.ecolind.2009.04.002

Kao, C. (1998). Performance of several nonlinear programming software packages on microcomputers. Computers and Operations Research, 25(10), 807-816.

Kim, R. Y. (2014). Asphalt pavements. London (U.K.): CRC Press.

Koczkodaj, W. W. (1993). A new definition of consistency of pairwise comparisons. Mathematical and Computer Modelling, 18(7), 79-84. doi:10.1016/08957177(93)90059-8

Koczkodaj, W. W., Szarek, S. J. (2010). On distance-based inconsistency reduction algorithms for pairwise comparisons. Logic Journal of the IGPL, 18(6), 859-869. doi:10.1093/jigpal/jzp062

Kucukvar, M., Gumus, S., Egilmez, G., Tatari, O. (2014). Ranking the sustainability performance of pavements: An intuitionistic fuzzy decision making method. Automation in Construction, 40, 33-43. doi:10.1016/j.autcon.2013.12.009

Lasdon, L. S., Waren, A. D., Jain, A., Ratner, M. (1978). Design and testing of a generalized reduced gradient code for nonlinear programming. ACM Transactions on Mathematical Software, 4(1), 34-50. doi:10.1145/355769.355773 
807

808

809

810

811

812

813

814

815

816

817

818

819

820

821

822

823

824

825

826

827

828

829

830

831

832

833

834

835

836

837

838

839

840

841

842

Lidicker, J., Sathaye, N., Madanat, S., Horvath, A. (2013). Pavement resurfacing policy for minimization of life-cycle costs and greenhouse gas emissions. Journal of Infrastructure Systems, 19(2), 129-137. doi:10.1061/(ASCE)IS.1943-555X.0000114

Lin, H. -. (2010). An application of fuzzy AHP for evaluating course website quality. Computers and Education, 54(4), 877-888. doi:10.1016/j.compedu.2009.09.017

Litzka, J., Goger, T., Malimban, C. (2008). Performance indicators for road pavements. ( No. 354). Vienna (Austria): European Cooperation in Science and Technology.

Microsoft Corporation. (2013). MS excel 2013. Redmond, Washington D.C. (U.S.):

Miller, G. A. (1956). The magical number seven, plus or minus two: Some limits on our capacity for processing information. Psychological Review, 63(2), 81-97. doi:10.1037/h0043158

Moretti, L., Di Mascio, P., D'Andrea, A. (2013). Environmental impact assessment of road asphalt pavements. Modern Applied Science, 7(11), 1-11. doi:10.5539/mas.v7n11p1

Nemry, F., Demirel, H. (2012). Impacts of climate change on transport: A focus on road and rail transport infrastructures. Luxembourg: Joint Research Centre (European Comission). doi:10.2791/15504

Nicholls, J. C., Carswell, I., James, D. J. (2012). Durability of thin surfacing systems in the UK after nine years monitoring. 5th Eurasphalt \& Eurobitume Congress, Istanbul (Turkey). (P5EE-113) 1-12.

Nikolaides, A. (2008). Very thin surfacing: A beneficial and cost effective alternative to traditional surfacing materials for flexible pavements. 1st ICTI China Beijing, Beijing (China). 131-140.

Nikolaides, A. (2014). Highway engineering: Pavements, materials and control of quality. New York (U.S.): CRC Press.

Noori, M., Tatari, O., Nam, B., Golestani, B., Greene, J. (2014). A stochastic optimization approach for the selection of reflective cracking mitigation techniques. Transportation Research Part A: Policy and Practice, 69, 367-378. doi:10.1016/j.tra.2014.09.006

OECD. (2005). Economic evaluation of long-life pavements. Paris (France): OECD Publishing.

Peláez, J. I., Lamata, M. T. (2003). A new measure of consistency for positive reciprocal matrices. Computers and Mathematics with Applications, 46(12), 1839-1845. doi:10.1016/S0898-1221(03)90240-9

Saaty, T. L. (1980). The analytic hierarchy process: Planning, priority setting, resource allocation. New York (U.S.): McGraw-Hill. 
843

844

845

846

847

848

849

850

851

852

853

854

855

856

857

858

859

860

861

862

863

864

865

866

867

868

869

870

871

872

873

874

875

876

877

878

879

880

Sandberg, U., Kragh, J., Goubert, L., Bendtsen, H., Bergiers, A., Biligri, K. P., . . . Vansteenkiste, S. (2010). Optimization of thin asphalt layers - state-of-the-art review. Linköping (Sweden): ERA-NET ROAD Project "Optimization of thin asphalt layers".

Sarja, A. (2010). Reliability principles, methodology and methods for lifetime design. Materials and Structures/Materiaux Et Constructions, 43(1-2), 261-271. doi:10.1617/s11527-009-9486-y

Sivilevicius, H. (2011). Application of expert evaluation method to determine the importance of operating asphalt mixing plant quality criteria and rank correlation. [Eksperthindamise meetodi juurutamine asfaltbetoonitehase kvaliteedikriteeriumi ja liigituse korrelatsiooni määramiseks] Baltic Journal of Road and Bridge Engineering, 6(1), 48-58. doi:10.3846/bjrbe.2011.07

Sivilevicius, H., Zavadskas, E. K., Turskis, Z. (2008). Quality attributes and complex assessment methodology of the asphalt mixing plant. Baltic Journal of Road and Bridge Engineering, 3(3), 161-166. doi:10.3846/1822-427X.2008.3.161-166

Tabaković, A., McNally, C., Gibney, A., Cassidy, S., Shahmohammadi, R., King, S., Gilbert, K. (2014). Recycling: Road construction in a post-fossil fuel society. report of laboratory and site testing for site trials. 1-13.

Tervonen, T., \& Lahdelma, R. (2007). Implementing stochastic multicriteria acceptability analysis. European Journal of Operational Research, 178(2), 500-513. doi:10.1016/j.ejor.2005.12.037

The MathWorks, I. (2014). MATLAB R2014b. Natick, Massachusetts (U.S.):

Van Leest, A. J., Van Harstkamp, S. B., Meijer, J. P. R. (2009). Decision support model for road pavements based on whole life costing, life cycle assessment and multicriteria analysis. [Modelo de apoyo a las decisiones para firmes basado en el coste total durante la vida útil, la evaluación del ciclo de vida y el análisis multicriterio] Carreteras, 4(166), 28-41.

Vose, D, (1996). Risk analysis: A quantitative guide. New York (U.S.): John Wiley \& Sons.

Wolfe, P. (1963). Methods of nonlinear programming. In R. L. Graves, \& P. Wolfe (Eds.), Recent advances in mathematical programming (pp. 67-86). New York (U.S.): MćGraw-Hill.

Wu, Z., Flintsch, G. W., Chowdhury, T. (2008). Hybrid multiobjective optimization model for regional pavement-preservation resource allocation. Transportation Research Record, 2084(2084), 28-37. doi:10.3141/2084-04

Xing, E. P., Ng, A. Y., Jordan, M. I., Russell, S. (2003). Distance metric learning, with application to clustering with side-information. Advances in Neural Information Processing Systems, 18, 1473-1480. 
881 Yeniay, O. (2005). A comparative study on optimization methods for the constrained 882 nonlinear programming problems. Mathematical Problems in Engineering, 2005(2), 883 165-173. doi:10.1155/MPE.2005.165

884 Zadeh, L. A. (1965). Fuzzy sets. Fuzzy Sets, Information and Control, 8(3), 338-353.

885 Zavadskas, E. K., Kaklauskas, A., Peldschus, F., Turskis, Z. (2007). Multi-attribute as886 sessment of road design solutions by using the COPRAS method. Baltic Journal of $887 \quad$ Road and Bridge Engineering, 2(4), 195-203.

888 Zavadskas, E. K., Liias, R., Turskis, Z. (2008). Multi-attribute decision -making methods 889 for assessment of quality in bridges and road construction: State-of-the-art surveys. 890 Baltic Journal of Road and Bridge Engineering, 3(3), 152-160. doi:10.3846/1822$891 \quad$ 427X.2008.3.152-160 